\title{
Measuring Oral health literacy in dental patients: Contribution towards preventive dentistry in Pakistan
}

\author{
Wardah Ahmed ${ }^{1}$ \\ Syed Muzzamil Ali Shah ${ }^{2}$ \\ Umer Khayyam ${ }^{3}$ \\ Tanzeela Sheikh ${ }^{4}$ \\ Natasha Anwer ${ }^{5}$
}

BDS, MSPH, PhD

BDS, Grad.Dip

BDS, MSc

BDS

BDS

\begin{abstract}
Oral health literacy (OHL) is essential for identification of ways to access health related information and its application to control over the healthy life. Oral health literacy covers knowledge and reading skills, understanding/comprehension and decision-making skills. This study aimed to measure the OHL level of patients attending private dental hospital.

METHODOLODY: Cross-sectional descriptive study design was used. After taking informed consent the validated modified structured Functional Oral Health Literacy questionnaire (OHL-L) was administered consisted of demography, oral health knowledge and oral health literacy items.

RESULTS: A total of 285 participants (131 male and 154 female) included in the study. The mean age of participants was 38.2 years (standard deviation [SD] $=1.3)$. Overall, 32(11.2\%) had inadequate, $164(57.5 \%)$ had marginal and $89(31.2 \%)$ had adequate oral health literacy. There was statistically significant difference among OHL-Levels with age groups $(\mathrm{p}=.001)$ and educational years $(\mathrm{p}=.002)$.

CONCLUSION: The study concluded that marginal oral health literacy pertaining in the adult patients visiting private dental hospital. There is a need to look at the health literacy in the context of large systems-social systems, cultural systems, education systems and public health systems. Further investigation is needed to develop appropriate intervention strategies to improve oral health literacy for better oral health outcomes. The effectiveness of the health program lies in the fact that people need to understand and interpret it correctly to lead a good quality of life.

KEY WORDS: MesH words: Oral Health Literacy, Functional health Literacy, Health Education, Preventive Dentistry, Oral Care.

HOW TO CITE: Ahmed W, Shah SMA, Khayyam U, Sheikh T, Anwer N. J Pak Dent Assoc 2017;26(4):176-80.

DOI: https://doi.org/10.25301/JPDA.264.176

Received: 13 October, 2017, Accepted: 23 November, 2017
\end{abstract}

\section{INTRODUCTION}

$\mathrm{O}$ ral health literacy (OHL) is widely accepted as an individual intangible resource to invest in individual empowerment. ${ }^{1}$ OHL is defined as "the degree to which individuals have the capacity to obtain, process and understand basic oral health information and services needed to make appropriate health decisions". ${ }^{2}$ Thus, OHL is essential for identification of ways to access health related information and its application to control over the healthy life. Therefore,

1. Senior Lecturer, dept of Community Health and Preventive Dentistry. Hamdard College of Medicine \& Dentistry, Hamdard University.

2. Assistant Professor, dept of Community Health and Preventive Dentistry. Hamdard College of Medicine \& Dentistry, Hamdard University.

3. Assistant Professor, dept of Orthodontics. Bhitai Dental \& Medical College. Lecturer, dept of Orthodontics. Hamdard College of Medicine \& Dentistry ,Hamdard University.

4. Senior House Officer, Dept of Periodontology. Hamdard College of Medicine \& Dentistry, Hamdard University.

Corresponding author: "Dr. Wardah Ahmed" < wardahahmed83@ hotmail.com > oral health literacy is a pathway to reduce oral health disparities in population. Oral health literacy covers knowledge and reading skills, understanding/comprehension and decision-making skills. ${ }^{3}$

The inclination of health services from curative to preventive aspects raises the importance of oral health literacy. Globally, many studies linked low OHL of the people with an overall inadequate oral health status, reduced dental appointment keeping behaviour, low understanding medicine leaflets and increased hospital admissions. ${ }^{4-6}$ Understanding level of OHL is essential for bridging the communication gap between patients and dentists. ${ }^{3}$ In Pakistan, there is limited literature that identifying barriers in local population. However, deficient communication, perceived health, general literacy level, language barriers and compromised general health status found to be major barriers in accessing other medical care. ${ }^{7}$ There is considerably high burden of oral diseases that are preventable and $\mathrm{OHL}$ 
has been associated with reduced incidence of oral diseases. ${ }^{5,8,9}$ Therefore, designing oral health education material according to oral health literacy level of population could help in accessing needed health information and elimination of the barriers. In our setting OHL documentation was found scarce and not measured. This study aimed to measure the OHL level of patients attending private dental hospital and it would facilitate the step towards preventive dentistry in Pakistan.

\section{METHODOLOGY}

Cross-sectional descriptive study design was used. The prevalence of $44.3 \%$ was taken as reference adequate health literacy among adults with 5\% margin of error, $95 \%$ confidence interval and the calculated sample size was $\mathrm{n}=285 .{ }^{3}$ Medical record number was used for simple random sampling. Every alternate patient with even number was recruited in the study. Patients' age 18 and above were included in the study. Patients on follow up visits and with severe dental pain or bleeding were excluded from the study. After taking informed consent the validated modified structured Functional Oral Health Literacy questionnaire $(\mathrm{OHL}-\mathrm{L})^{3}$ was administered, consisted of 20 items. The questionnaire consists of demography, oral health knowledge and items to investigate individual's:

a) Capacity to access; reading and listening (e.g. questions about information sources, preventive strategies, history forms, appointment card)

b) Capacity to process or understand; numeracy skills, understanding of treatment and alternatives (e.g. questions about prescription after extraction, pre and post instructions by dentists)

c) Capacity for decision making skills (e.g. questions about different clinical scenarios such as regarding caries, periodontal disease and oral cancer)

Data collected by principal investigator and two trained house surgeons. Inter-interviewer reliability contained by piloting the questionnaire among 20 patients. The "correct" answers were labeled as 1 and "incorrect" as 0 . OHL-L divided in three levels. Cut off values were 0-9 for inadequate OHL, 10-15 marginal OHL and 16-20 for adequate OHL. ${ }^{3,10}$ Primary objective was to measure oral health literacy and categorize the patients in OHL-levels. Secondary objective was to assess the difference in OHL-L among various age groups, gender, education and profession.

SPSS version 20.0 was used for statistical analysis. Cronbach's alpha was used for questionnaire reliability assessment. Frequency, percentages (gender, age, education and profession), mean and standard deviation (age) were employed as descriptive statistics. Chi square test was used for calculating statistically significance difference of OHLL among demographic variables.

\section{RESULTS}

\section{Participants:}

A total of 285 participants (131 male and 154 female) were selected in the study. The mean age of participants was 38.2 (standard deviation $[\mathrm{SD}]=1.3$ ) ranging from 18 to 69 years. The characteristics of study sample are shown in table 1.

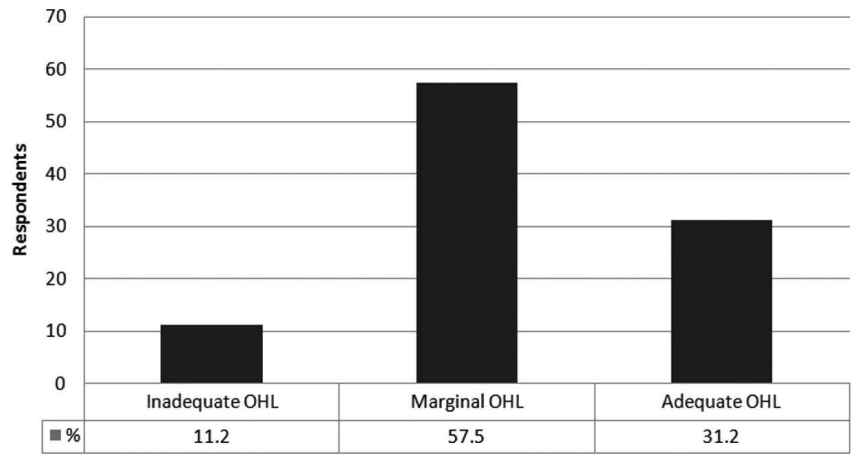

Figure I: Percentage of particioants in OHL-Levels (OHL-Oral Health Literacy

\section{Descriptive findings:}

Overall, 32(11.2\%) had inadequate, 164(57.5\%) had marginal and $89(31.2 \%)$ had adequate oral health literacy (Figure 1).There was statistically significant difference among OHL-L with age groups $(p=.001)$ and educational years $(p=.002)$. However, no statistically significant difference between male and female oral health literacy $(p=.40)$ was

\begin{tabular}{|c|c|c|c|c|c|c|}
\hline Variables & $\mathrm{n}^{*}$ & $\%$ & $\begin{array}{c}\text { Inadequate } \\
\text { OHL } \\
n\end{array}$ & $\begin{array}{l}\text { Margin } \\
\text { OHL } \\
\quad n \\
\end{array}$ & $\begin{array}{l}\text { Adequate } \\
\text { OHL } \\
\quad n\end{array}$ & $p$-value** \\
\hline Gender & & & & & & \multirow{4}{*}{0.40} \\
\hline Male & 131 & 46 & 17 & 70 & 44 & \\
\hline Female & 154 & 54 & 15 & 94 & 45 & \\
\hline Total & 285 & 100 & 32 & 164 & 89 & \\
\hline Age Groups & & & & & & \multirow{5}{*}{0.001} \\
\hline $18-29$ & 88 & 30.9 & 14 & 60 & 14 & \\
\hline $30-49$ & 140 & 49.1 & 9 & 76 & 55 & \\
\hline $50-69$ & 57 & 20.0 & 9 & 28 & 20 & \\
\hline Total & 285 & 100 & 32 & 164 & 89 & \\
\hline Educational Years & & & & & & \multirow{7}{*}{0.02} \\
\hline Primary-Intermediate & 115 & 40.3 & 15 & 64 & 36 & \\
\hline Bachelor & 117 & 41.0 & 14 & 71 & 32 & \\
\hline Master & 24 & 8.4 & 2 & 14 & 8 & \\
\hline More & 5 & 1.7 & 0 & 2 & 3 & \\
\hline Not Mentioned & 24 & 8.4 & 6 & 10 & 8 & \\
\hline Total & 285 & 100 & 37 & 161 & 87 & \\
\hline Occupation & & & & & & \multirow{8}{*}{0.82} \\
\hline No job & 40 & 14.0 & 4 & 24 & 12 & \\
\hline Housewife & 86 & 30.1 & 6 & 51 & 29 & \\
\hline Medical & 14 & 5 & 2 & 9 & 3 & \\
\hline Education & 18 & 6.3 & 1 & 9 & 10 & \\
\hline Other(Business, Engineer etc) & 104 & 36.4 & 21 & 58 & 30 & \\
\hline Student & 23 & 8.0 & 5 & 12 & 6 & \\
\hline Total & 285 & 100 & 32 & 163 & 90 & \\
\hline
\end{tabular}

Table 1: Frequency distribution of respondents among OHL-Levels with respect to demographic variables 
found. Similarly, no difference among professions $(p=.82)$ and OHL-L was observed (Table 1).

Responses of each item of functional oral health literacy questionnaire were tabulated in Table 2. The major source of oral health information was found to be television $101(35.4 \%)$. Respondents found difficulty in understanding dental education materials and magazines 166(59.3\%).

\begin{tabular}{|c|c|c|c|c|}
\hline \multirow[t]{2}{*}{ OHL-L $(n=285)$} & \multicolumn{2}{|c|}{ Yes } & \multicolumn{2}{|c|}{ No } \\
\hline & $\mathbf{n}$ & $\%$ & $\mathbf{n}$ & $\%$ \\
\hline ACCESS: READING ,LISTENING & 216 & 75.8 & 69 & 24.2 \\
\hline Ability to read English & 150 & 52.6 & 135 & 47.4 \\
\hline Ability to answer History Forms & 169 & 59.3 & 116 & 40.7 \\
\hline \multicolumn{5}{|l|}{$\begin{array}{l}\text { Ability to read Dental Magazines and Educational Material } \\
\text { Dental Related Information Source: }\end{array}$} \\
\hline Newspaper & 58 & 20.4 & 227 & 79.6 \\
\hline Television & 101 & 35.4 & 184 & 64.6 \\
\hline Radio & 21 & 7.4 & 264 & 92.6 \\
\hline Internet & 55 & 19.3 & 230 & 80.7 \\
\hline Dentist & 98 & 34.4 & 187 & 65.6 \\
\hline Family, Friends, Relatives & 166 & 58.2 & 119 & 41.8 \\
\hline & Correct & & Incorrect & \\
\hline \multicolumn{5}{|l|}{ UNDERSTAND: NUMERACY, COMPREHENSION } \\
\hline Ability to understand Dental Magazines and Educational Material & 169 & 59.3 & 116 & 40.7 \\
\hline Ability to understand Instructions given by Dentist & 233 & 81.8 & 52 & 18.2 \\
\hline Ability to understand Appointment Card & 212 & 74.4 & 73 & 25.6 \\
\hline Ability to understand Prescription Card & 184 & 64.6 & 101 & 35.4 \\
\hline Ability to understand $1+1+1,500 \mathrm{mg}$,TDS & 171 & 60.0 & 114 & 40.0 \\
\hline Medication continuous even after symptoms subsides & 177 & 62.1 & 108 & 37.9 \\
\hline Ability to understand the current dental treatment procedure & 48 & 83.2 & 237 & 16.8 \\
\hline Radiograph is always necessary & 241 & 84.6 & 44 & 15.4 \\
\hline Single and multiple visits can be required for any dental procedure & 245 & 86.0 & 40 & 14.0 \\
\hline \multicolumn{5}{|l|}{ DECISION-MAKING } \\
\hline Ability to choose among the treatment alternatives & 203 & 71.2 & 82 & 28.8 \\
\hline Correct decision if little bleeding occurs after brushing or flossing? & 143 & 50.2 & 142 & 49.8 \\
\hline Correct decision if pain and swelling occur in month? & 170 & 59.6 & 115 & 40.3 \\
\hline Correct decision to remove stains? & 161 & 56.5 & 124 & 43.5 \\
\hline Blood pressure and Sugar level should be check prior dental treatment? & 232 & 81.4 & 53 & 18.6 \\
\hline Removal of gauze at right time after extraction & 194 & 68.1 & 91 & 30.2 \\
\hline Eating of hot food at right time after extraction & 91 & 30.2 & 194 & 68.1 \\
\hline
\end{tabular}

Table 2: Responses of each item Functional Oral health literacy (OHL)-L*

Majority of respondents found difficulty in understanding instructions given by dentist 233(81.8\%).Similarly, respondents found difficulty in correct decision if they are having $b$ leeding gums while brushing and flossing $143(50.2 \%)$.

\section{Reliability:}

The Cronbach's alpha coefficient was found to be 0.828 that interpret as the good internal consistency reliability.

\section{Validity:}

Comparison was made among different variables. Previously, it was hypothesized that questionnaire discriminated well among the study subgroups that differed in education. Majority of participants lied in adequate OHL -L had bachelor degree (37\%).

\section{DISCUSSION}

The results specify that more than half $(57.5 \%)$ of the study participants had marginal health literacy. The reason could be the study was conducted in urban private hospital with better general literacy level. Similar to other studies, people have low education level scored low in OHLscales. $(11,12)$ Likewise, other study conducted by Rai S. in the private dental setting found more than half $(67 \%)$ respondents lied in medium OHL-level.(10) Contrary to this, Naghibi S. reported $16.2 \%$ respondents had marginal OHL and $39.2 \%$ had inadequate OHL in general population.(3)Hence, in dental hospitals patients already receiving health information and getting treatments could impact on the OHL scores. Nevertheless, to reduce selection bias and over estimation of the OHL scores, present study conducted on the randomly selected patients who attended dental hospital for the first time.

Findings of the present study showed the significant association of age with OHL. These findings are in accordance with Rai S. and D'Curz. ${ }^{10,13}$ However, Naghibi $\mathrm{S}$ and Tam A found no association of age with OHL. ${ }^{3,14}$ Contrary to his finding other study by Holtznam JS et. al found that OHL decreases with increasing age. ${ }^{4}$ In present study almost half of the respondents $(49.1 \%)$ belonged to age group 30-49 years and majority of respondents (30\%) were housewives. This may also interpreted as they are dependent on their spouse or children for decision making. Results also showed majority of the respondents have been associated with any profession and thus, could increase their information sources. However, it is widely accepted that there is no association of gender with OHL. ${ }^{3,4,10}$

In literature majority of the researchers used oral health literacy instruments in dental settings to measure the level of OHL in patients. Most widely used are Rapid estimate of adult literacy-dentistry (REALD). ${ }^{11,15}$ Adult Health literacy instrument for Dentistry (AHLID) ${ }^{16}$ and Health literacy skills instrument (HLSI) ${ }^{17}$ etc. In present study functional oral health literacy instrument have been used. To the best of our knowledge it for the first time that in any dental hospital OHL-Level of the patients have been measured. OHL-L has additionally decision making component contrary to other instruments which only include reading and understanding components of the health literacy.

In developing countries emphasize have not been given on the oral-health related information, lack of sensitization of dentists about oral health literacy needs, complicated dental magazines and materials. ${ }^{18}$ Although more than half of respondents had ability to read English and dental magazines/materials in present study, however, majority of them seek help to fill history forms and understanding the actual meaning of dental magazines/materials. Majority of the participants had accessed information from family, friends, relatives, television and dentists consistent with 
the findings from study. ${ }^{10}$ Social interactions have the powerful impact on the individual in Pakistan. ${ }^{19}$ Dentists as the direct source of information should avoid medical jargon and clearly understand the level of oral health literacy of their patients to reduce the communication barrier. ${ }^{20,21}$ This could be interpreted as even better OHL, people lacking in decision making abilities that may hinder in better oral health status. Flynn p et. al in their study assessed improved communication between dental hygienists and patients after assessing their OHL-Level. ${ }^{22}$ Results showed many of the respondents facing difficulty in understanding appointment cards, prescription cards and post treatment instructions. They compromised in decision making for opting treatments. These findings are consistent with Rai $\mathrm{S}$ and Baskaradoss $\mathrm{J} .{ }^{10,23}$ Tam $\mathrm{A}$ et. al explored the association of OHL with patient's dental knowledge, understanding and interpretation of oral health information provided through dental written materials. They recommend to incorporating the measured oral health literacy approach to increase the ability of understanding and decision making of the patients. ${ }^{14}$

In several dental researches it has been evidently proved that OHL associated with better dental appointment keeping behavior, ${ }^{6,23}$ people with dysfunctional ability to socially interact and self expression (alexithymia), ${ }^{24}$ better children oral health status, ${ }^{9}$ regular follow up care,(15) low prevalence of caries and periodontal disease. ${ }^{5}$ Therefore, OHL considered as the way to access and understand oral health information, interpret the information correctly and implicate in correct decision making.

The current study conducted in urban private hospital setting thus, the external generalizability is questionable. Hence, the future research would be planned to measure OHL in general population of the same area and different areas of the city to determine more precise oral health literacy level of the population. Moreover, patients visiting hospitals were not screened if they visited any private dental clinic prior; this could over estimate the results.

\section{CONCLUSION}

The study found marginal oral health literacy in adult population visiting private dental hospital. There is a need to look at the oral health literacy in the context of large systems-social systems, cultural systems, education systems and public health systems. Further investigation is needed to develop appropriate intervention strategies to improve oral health literacy for better oral health outcomes. The effectiveness of the program lies in the fact that people need to understand and interpret it correctly to lead a good quality of life.

\section{ACKNOWLEDGEMENT}

Acknowledging all the participants contributing in the study.

\section{DISCLAIMER}

The article has not been presented in a conference or published in any abstract book.

\section{CONFLICT OF INTEREST}

None to declare.

\section{FUNDING DISCLOSURE}

None to declare.

\section{REFERENCES}

1. Nutbeam D. The evolving concept of health literacy. Soc Sci Med. 2008 Dec 31;67:2072-8.

2. US Department of Health and Human Services, Office of Disease Prevention and Health Promotion. Healthy People 2010: Understanding and improving health and objectives for improving health. Washington, DC: US Department of Health and Human Services. 2000.

3. Naghibi Sistani MM, Montazeri A, Yazdani R, Murtomaa H. New oral health literacy instrument for public health: development and pilot testing. $\mathrm{J}$ investig clin dent. 2014;5:313-21.

4. Holtzman JS, Atchison KA, Gironda MW, Radbod R, Gornbein J. The association between oral health literacy and failed appointments in adults attending a university?based general dental clinic. Community dent oral epidemiol. 2014;42:263-70.

5. Kanupuru KK, Fareed N, Sudhir KM. Relationship Between Oral Health Literacy and Oral Health Status Among College Students. Oral Health Prev Dent.2015;13. 6. Lapidos A, Shaefer HL, Gwozdek A. Toward a better understanding of dental appointment?keeping behavior. Community Dent Oral Epidemiol. 2016;44:8591.

7. Irfan FB, Irfan BB, Spiegel DA. Barriers to accessing surgical care in Pakistan: healthcare barrier model and quantitative systematic review. J Surg Res. 2012;176:8494.

8. Richards D. Oral diseases affect some 3.9 billion people. Evid Based Dent. 2013;14:35.

9. Bridges SM, Parthasarathy DS, Wong HM, Yiu CK, Au TK, McGrath CP. The relationship between caregiver functional oral health literacy and child oral health status. 
Patient Educ Couns. 2014 Mar 31;94:411-6.

10. Rai S, Shodan M, Shetty PJ. Conceptual measure of oral health literacy level among patients visiting a private dental institution in Dharwad: A cross-sectional questionnaire study. J Ind Assoc Public Health Dent.2015;1:492. 11. Lee JY RR, Lee SY, Bender D, Ruiz RE. Development of a word recognition instrument to test health literacy in dentistry: the REALD-30 a brief communication. J Public Health Dent. 67. 2007:94-8.

12. Atchison KA GM, Messadi D, Der-Martirosian C. Screening for oral health literacy in an urban dental clinic. J Public Health Dent.. 2010;70:269-75.

13. D'Cruz AM SAM. Health literacy among Indian adults seeking dental care. Dent Res J (Isfahan) 2013;10:20-4. 14. Tam A YO, Atchison KA, Richards JK, Holtzman JS. The association of patients' oral health literacy and dental school communication tools: a pilot study. J Dent Educ. 2015;79:530-8.

15. Gironda M D-MC, Messadi D, Holtzman J, Atchison K. A brief 20-item dental/medical health literacy screen (REALMD-20 J Public Health Dent. 2013;73:50-5. 16. Stein L, Pettersen KS, Bergdahl M, Bergdahl J. Development and validation of an instrument to assess oral health literacy in Norwegian adult dental patients. Acta Odontol Scand. 2015;73:530-8.

17. Bann CM ML, Berkman ND, Squiers LB. The Health Literacy Skills Instrument: a 10-item short form. J Health
Commun. 2012;17:191-202.

18. National Institute of Health (NIH). The invisible barrier: literacy and its relationship with oral health. A report of a workgroup sponsored by the National Institute of Dental and Craniofacial Research, National Institutes of Health. J Public Health Dent 2005; 65: 174-82.

19. Harchandani N. Oral health challenges in Pakistan and approaches to these problems. Pak Oral Dent J 2012;3:497501 .

20. Barriers and Soulitions to Accessing care. The Academy of General Dentistry (AGD)was developed by the AGD Board. [online] 2012 [ cited 2017 Jan 15]. Available from URL: https://www.agd.org/media/380239/Barriers-andSolutions-to-Accessing-Care.pdf2012.

21. Boles CD LY, November-Rider D. Readability Levels of Dental Patient Education Brochures. J Dent Hygienist. 2016;90:28-34.

22. Flynn P AA, Schwei K, VanWormer J, Skrzypcak K. Assessing Dental Hygienists' Communication Techniques for Use with Low Oral Health Literacy Patients. J Dent Hygienist.2016;9:162-9.

23. Baskaradoss JK. The association between oral health literacy and missed dental appointments. J Am Dent Assoc. 2016;147:867-74.

24. Stein L BM, Pettersen KS, Bergdahl J. Exploring the association between oral health literacy and alexithymia. Community Dent Health. 2015;32:143-7. 